\title{
MULTI-CRITERIA EXPERIMENTAL COMPARISON OF BATTERIES CIRCUITAL MODELS FOR AUTOMOTIVE APPLICATIONS
}

Electrochemical batteries used in energy storage systems provide a significant contribution to the development of smart grids and green transportation. In recent years, intensive research activities have been oriented to the optimal management of energy storage systems for power electronics applications in fast growing industrial sectors as EVs and HEVs. The accurate modeling of electrochemical batteries is fundamental in the design of control algorithms applied to energy storage systems. Focusing on automotive applications, in this paper a comprehensive analysis of ESS models based on equivalent electric circuits using a multi-criteria approach is presented. An extensive experimental validation has been carried out to evaluate the performance of battery models in automotive applications.

Keywords: battery modeling, SOC estimation, SOH estimation, energy storage systems, automotive

\section{Introduction}

The energy management of storage systems based on electrochemical batteries is one of the most investigated topics in smart grid and transportation issues [1]. In particular, in EV and HEV applications the battery pack requires a Battery Management System BMS to optimize the control strategies in terms of safety and performance. Such control strategies are usually implemented on Energy Storage System (ESS) exploiting a suitable model of the battery pack that ensure an appropriate accuracy in the estimation of State of Charge (SOC) and State of Health ( $\mathrm{SOH}$ ) while avoiding too large computational complexity. In the field of power electronics for automotive applications, the trade-off between the response accuracy and the computational effort is obtained by using models based on equivalent electric circuits [2].

In BMS applications, a significant example about the influence of the ESS circuit model can be reported by considering SOC estimation methods based on observers [3, 4]. This category includes sliding mode, Luenberger, PI-based and other similar observers. Their implementation always leads to the use of parameter-varying circuit models. In Figure 1, the schematic representation of a generic PI-based observer is shown [5]. In such a case, the correctness of SOC and $\mathrm{SOH}$ estimations is strongly related to the accuracy of the circuit model response. In particular, considering demanding application that shows huge current range, the circuit model can provide a wrong voltage estimation that implies large errors in the ESS state evaluation.

In recent years, several authors have carried out some reviews about models for ESS. Significant examples are in [6-8]. From a review of the existing literature, it can be stated that a comprehensive analysis on battery circuit models cannot be conducted by considering a single comparison criterion. In this paper, a comparison of different equivalent circuits used to model battery packs in the automotive field has been reported on the basis of a multi-criteria analysis, also considering large experimental data.

\section{Energy storage systems modeling}

It is possible to sort the main circuit models for ESS used in the automotive field in a few main categories, as listed in the following.

\section{- $\quad$ Basic Models}

The basic circuit used to model a battery is the series connection of a voltage generator $E_{0}$ and a resistor $R_{i}$ [8]. This equivalent circuit is shown in Table 3 - model A. $E_{0}$ is the no-load voltage at full charge state while $R_{i}$ models the internal and

\footnotetext{
* Giovanni Nobile, Mario Cacciato, Giuseppe Scarcella, Giacomo Scelba Department of Electrical, Electronics Engineering and Computer Science, University of Catania, Italy E-mail: giovanni.nobile@dieei.unict.it
} 


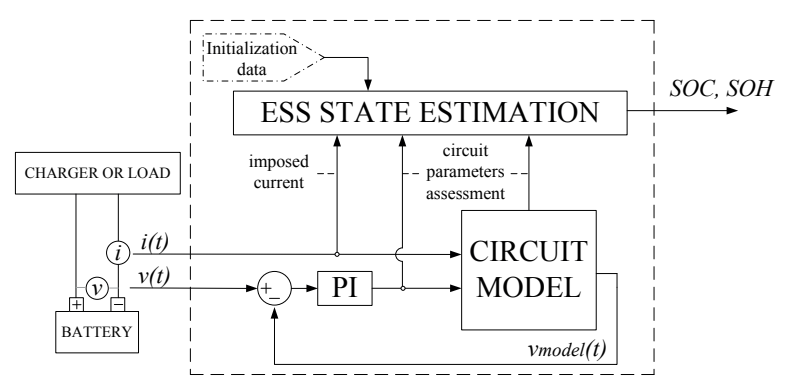

Figure 1 PI-based observer scheme including the battery circuit model

terminal resistances. Higher accuracy can be obtained by taking into account the function $R_{i}$ (SOC) [8].

- Sheperd, Unnewehr and Nernst models

These models are obtained starting from stoichiometric electrochemical formulations. Different models belong to this category and have been proposed by Sheperd, Unnewehr and Nernst [7]. The basic Sheperd formulation is in stoichiometric form, anyway a transition to a simpler equivalent electric circuit model can be obtained by considering acceptable approximations. A popular simplified version, cited in [7], is displayed in Table 3 - model C:

$v_{\text {model }}(t)=E_{0}-R_{i} \cdot i(t)-\frac{\mu}{S O C}$

where $\mu_{s}$ is a constant term which models the variation of the voltage waveform $v_{\text {model }}$ as a function of the actual SOC. A similar formulation can be reported for the Unnewehr and Nernst models represented in Table 3 - model D and E, respectively.

- RC linear models

The basic RC linear model is shown in Table 3 - model F. The RC network $R_{d} C_{d}$ is used to plot the transient behavior of ESS during current steps [7, 8]. In some applications extra RC networks are included to increase accuracy in voltage estimation during transients. A modified version of the previous model is the Thevenin model [8], represented in Table 3 - model G. A functional relation is introduced between the no-load voltage $E_{0}$ and the actual SOC. An additional resistor $R_{s d}$ is often included to take into account the self-discharge phenomena, [9].

- $\quad$ Runtime models

In the "runtime models" the electric circuit is split in two or three sections [6] as shown in Table 3 - model H. The first section models the voltage response during a charge or a discharge. A secondary section provides an estimation of the actual SOC estimation from the voltage on a capacitor $C_{\text {capacity }}$ whose capacitance value depends on $\mathrm{SOH}$. An advanced runtime model capable of model runtime and current-voltage (IV) waveforms, while reducing the complexity is reported in [10]. Such model is represented in Table 3 - model I.

- Tremblay and Jackey models
The main software houses in the field of power electronics for automotive applications have developed specific battery models to be integrated into their simulations platforms. An overview of these models is in [8]. In [11] Tremblay et al. have proposed an equivalent circuit model derived from Sheperd formulation. This model can be used for Lead Acid batteries, Nickel Cadmium and Ni-MH technologies. Another ESS model has been proposed by Jackey, considering the target of a fast implementation in electronic circuit simulations by performing some approximations [12].

\section{- Randles models}

In this equivalent circuit models category some of the circuit elements are time-varying parameters. Their value depends on the actual SOC and $\mathrm{SOH}$ as well as on external conditions (e.g. current rate and temperature). Randles model is often used in combination with Kalman Filter (KF). A significant example is in [13]. The typical configuration of the Randles circuit is shown in Table 3 - model L. The capacitance $C_{b u l k}$ models the main charge store, its voltage is an indicator of SOC, its capacitance is related to actual $\mathrm{SOH}$.

\section{- Other circuit models}

Many other circuit models can be found in literature. Some of them are obtained from the numerical elaboration of a significant amount of experimental data collected for a given application. Unfortunately, in these cases, it is usually impossible to re-use the same model for different operating scenarios. Two significant examples, presented in [14], are the CIEMAT model and the Monegon model. In [15] an impedance modeling for lead acid batteries is presented by Salkind et al. Experimental data from the Electrochemical Impedance Spectroscopy (EIS) lead to a series impedance model, as described in [16]. Another circuit which is fairly widespread is usually named as "third order model" [17]. Basic concept is related to parasitic effects during charge operation. A parasitic branch is added to a basic Thevenin topology.

\section{Comparative evaluation of ESS circuit models}

\section{Features and performance comparison}

In Table 1, the information collected from a comprehensive literature review about the battery circuit models in the automotive field are summarized. It can be easily observed that none of the models can totally fulfill all the requirements. Besides, the inclusion of additional parameters in the equivalent circuits and/ or the exploitation of parameter-varying models can satisfy many requirements e.g. memory effect, temperature influence and so on. In parameter-varying models, the parameters have to be continuously tuned by using real-time estimation algorithms.

In terms of applications and technologies that can be associated to each model category, Figure 2 shows that almost all the battery models fit different battery technologies. On 


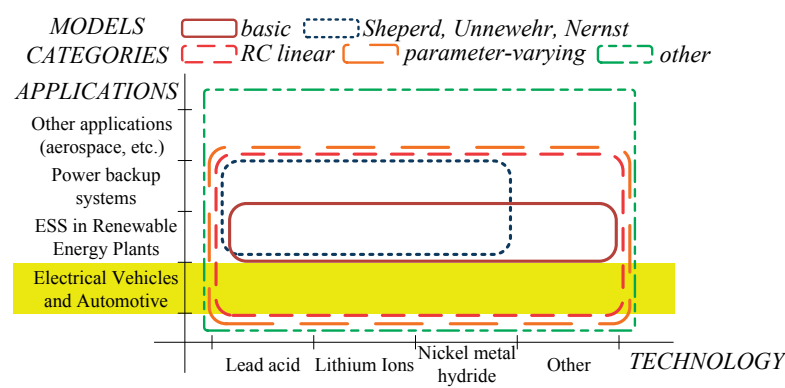

Figure 2 Comparison based on applications and technologies

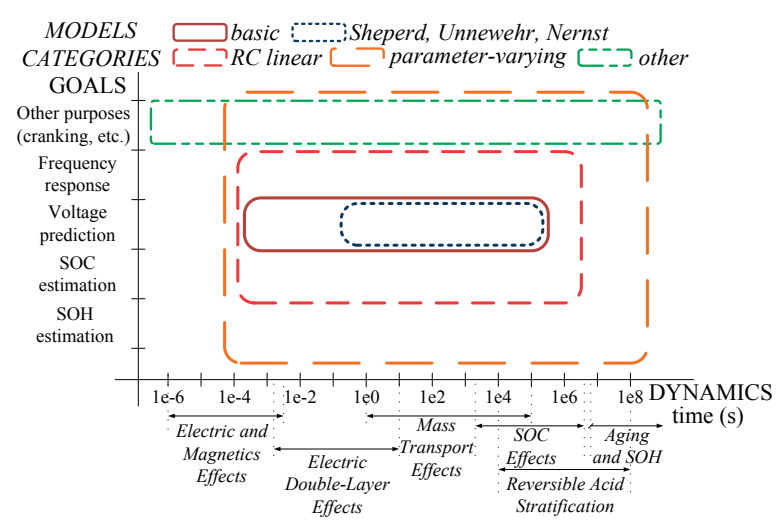

Figure 3 Comparison based on goals and dynamics

the contrary, referring to automotive applications, the simplest models are usually not suitable to be used in this challenging field. In Figure 3 the models are classified on the basis of the frequency range related to the main goals in ESS modeling. From this chart, it is quite evident that only more complex models can be used in a large frequency range to fulfill several modeling goals. On the contrary, the simpler models are usually devoted to the voltage estimation only while the estimation of SOC and $\mathrm{SOH}$ requires additional algorithms and/or more complicated models. Moreover, the bandwidth for the simpler models can be sometimes too narrow for an effective implementation in the automotive field.

\section{Experimental comparison}

A large amount of experimental tests has been done using the test bench shown in Figure 4, technical data of the main components are in Table 2. The power converter used to supply AC loads is displayed in Figure 5. The first stage is a $50 \mathrm{kHz}$ pushpull DC/DC converter connected to the $24 \mathrm{~V}_{\mathrm{DC}}$ VRLA battery pack and controlled in order to obtain a stable $430 \mathrm{~V}$ DC bus. The second stage is a $17 \mathrm{kHz}$ PWM VSI sine wave inverter connected to the DC bus and controlled to ensure a stable $230 \mathrm{~V}_{\mathrm{AC}} 50 \mathrm{~Hz}$ output $[18,19]$. The overall efficiency of the converter at rated load is $95 \%$. The control firmware has been developed in a 32 bit $72 \mathrm{MHz}$ Micro Controller Unit (MCU)

The performance of each model is evaluated by comparing the waveform of the measured battery voltage with the voltage

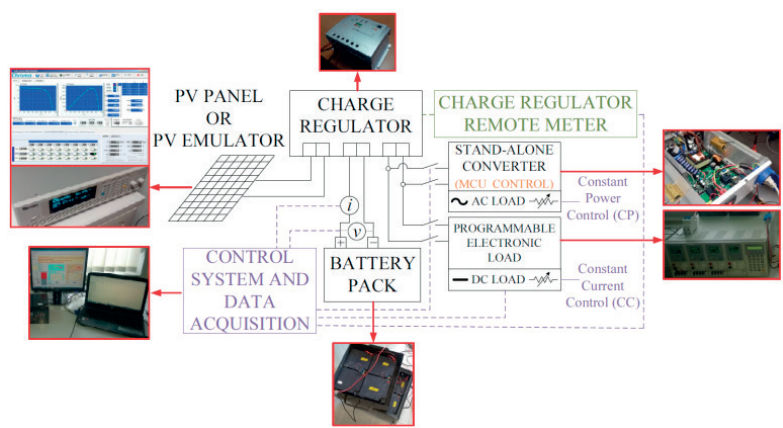

Figure 4 Schematical representation of the experimental setup

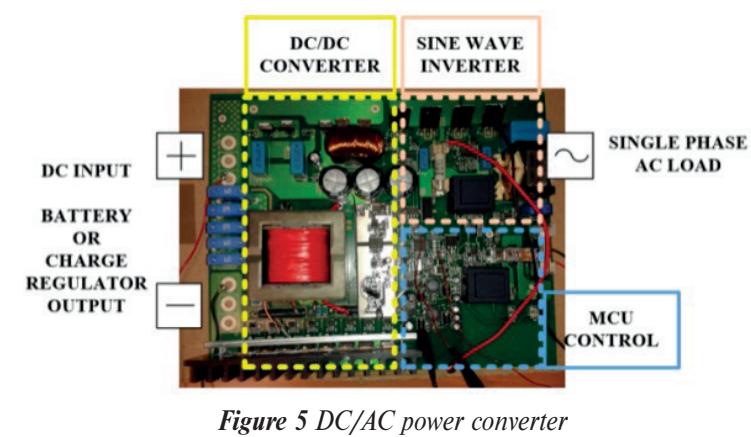

waveform provided by the equivalent circuits. In order to assign an analytical evaluation of the accuracy, some numerical indexes have been introduced.

For each model, the identification of parameters is not trivial. In order to perform an appropriate comparison between the models, a constrained minimums formulation has been implemented for the identification of parameters in every models. Input data is the forced current $i(t)$ and the corresponding voltage $v(t)$ measured at battery terminals. The experimental tests are carried out at different current rates $C_{R}$, the environmental temperature ranges between $20^{\circ} \mathrm{C}$ and $40^{\circ} \mathrm{C}$. Referring to a generic equivalent circuit, the Kirchhoff's Voltage Law is:

$v_{\text {model }, k}=h_{k 1} \cdot x_{1}+h_{k 2} \cdot x_{2}+\ldots+h_{k n} \cdot x_{n}$

hence, for $N$ tests:

$\left[\begin{array}{c}v_{\text {model }, 1} \\ v_{\text {model }, 2} \\ \ldots \\ v_{\text {model }, \mathrm{k}} \\ \ldots \\ v_{\text {model }, \mathrm{N}}\end{array}\right]=\left[\begin{array}{cccc}h_{11} & h_{12} & \ldots & h_{1 n} \\ h_{21} & h_{22} & \ldots & h_{2 n} \\ \ldots & \ldots & \ldots & \ldots \\ h_{k 1} & h_{k 2} & \ldots & h_{k n} \\ \ldots & \ldots & \ldots & \ldots \\ h_{N 1} & h_{N 2} & \ldots & h_{N n}\end{array}\right] \cdot\left[\begin{array}{c}x_{1} \\ x_{2} \\ \ldots \\ x_{n}\end{array}\right]$

$\left[V_{\text {model }}\right]=[H] \cdot[X]$

$k$ is a time index and $h_{k i}$ is a term about the relation between $v_{\text {model, } k}$ and parameter $x_{i}$. Thanks to the implementation of the 
Table 1 Models comparison based on main requirements

\begin{tabular}{|c|c|c|c|c|c|c|c|c|c|c|c|c|c|c|}
\hline \multicolumn{2}{|l|}{ Models (*) } & \multicolumn{13}{|c|}{ Requirements or performance $(* *)$} \\
\hline Category & ID & 1 & 2 & 3 & 4 & 5 & 6 & 7 & 8 & 9 & 10 & 11 & 12 & 13 \\
\hline \multirow{2}{*}{ Basic models } & A & $\mathrm{X}$ & $\mathrm{O}$ & $\mathrm{O}$ & $\mathrm{O}$ & $\mathrm{O}$ & 0 & $\mathrm{O}$ & $\mathrm{O}$ & $\mathrm{O}$ & $\mathrm{O}$ & $\mathrm{O}$ & $\mathrm{O}$ & $\mathrm{O}$ \\
\hline & $\mathrm{B}$ & $\mathrm{X}$ & $\mathrm{O}$ & $\mathrm{O}$ & $\mathrm{O}$ & $\mathrm{O}$ & $\mathrm{O}$ & $\mathrm{O}$ & $\mathrm{O}$ & $\mathrm{O}$ & $\mathrm{O}$ & $\mathrm{O}$ & $\mathrm{O}$ & $\mathrm{O}$ \\
\hline \multirow{3}{*}{$\begin{array}{c}\text { Sheperd, } \\
\text { Unnewehr and } \\
\text { Nernst }\end{array}$} & $\mathrm{C}$ & $\mathrm{X}$ & $\mathrm{O}$ & $\mathrm{O}$ & $\mathrm{O}$ & $\mathrm{O}$ & $\mathrm{O}$ & $\mathrm{O}$ & $\mathrm{O}$ & $\mathrm{O}$ & $\mathrm{O}$ & $\mathrm{O}$ & $\mathrm{O}$ & $\mathrm{O}$ \\
\hline & $\mathrm{D}$ & $\mathrm{X}$ & $\mathrm{O}$ & $\mathrm{O}$ & $\mathrm{O}$ & $\mathrm{O}$ & $\mathrm{O}$ & $\mathrm{O}$ & $\mathrm{O}$ & $\mathrm{O}$ & $\mathrm{O}$ & $\mathrm{O}$ & $\mathrm{O}$ & $\mathrm{O}$ \\
\hline & $\mathrm{E}$ & $\mathrm{X}$ & $\mathrm{O}$ & $\mathrm{O}$ & $\mathrm{O}$ & $\mathrm{O}$ & $\mathrm{O}$ & $\mathrm{O}$ & $\mathrm{O}$ & $\mathrm{O}$ & $\mathrm{O}$ & $\mathrm{O}$ & $\mathrm{O}$ & $\mathrm{O}$ \\
\hline \multirow{2}{*}{$\mathrm{RC}$ linear models } & $\mathrm{F}$ & $\mathrm{X}$ & $\mathrm{X}$ & $\mathrm{O}$ & $\mathrm{O}$ & $\mathrm{O}$ & $\mathrm{O}$ & $\mathrm{O}$ & $\mathrm{O}$ & $\mathrm{O}$ & $\mathrm{O}$ & $\mathrm{O}$ & $\mathrm{O}$ & $\mathrm{O}$ \\
\hline & G & $\mathrm{X}$ & $\mathrm{X}$ & $\mathrm{O}$ & $\mathrm{X}$ & $\mathrm{X}$ & $\mathrm{O}$ & $\mathrm{O}$ & $\mathrm{O}$ & $\mathrm{O}$ & $\mathrm{O}$ & $\mathrm{O}$ & $\mathrm{O}$ & $\mathrm{O}$ \\
\hline \multirow{5}{*}{$\begin{array}{l}\text { Parameter-varying } \\
\text { models }\end{array}$} & $\mathrm{H}$ & $\mathrm{X}$ & $\mathrm{X}$ & $\mathrm{O}$ & $\mathrm{X}$ & $\mathrm{X}$ & 0 & $\mathrm{X}$ & $\mathrm{O}$ & $\mathrm{O}$ & $\mathrm{X}$ & $\mathrm{O}$ & $\mathrm{O}$ & $\mathrm{O}$ \\
\hline & I & $\mathrm{X}$ & $\mathrm{X}$ & $\mathrm{X}$ & $\mathrm{X}$ & $\mathrm{X}$ & $\mathrm{O}$ & $\mathrm{X}$ & $\mathrm{X}$ & $\mathrm{O}$ & $\mathrm{X}$ & $\mathrm{O}$ & $\mathrm{O}$ & $\mathrm{O}$ \\
\hline & $\mathrm{J}$ & $\mathrm{X}$ & $\mathrm{X}$ & $\mathrm{O}$ & $\mathrm{O}$ & $\mathrm{X}$ & $\mathrm{O}$ & $\mathrm{X}$ & $\mathrm{X}$ & $\mathrm{X}$ & $\mathrm{O}$ & $\mathrm{O}$ & $\mathrm{O}$ & $\mathrm{O}$ \\
\hline & $\mathrm{K}$ & $\mathrm{X}$ & $\mathrm{O}$ & $\mathrm{O}$ & $\mathrm{X}$ & $\mathrm{X}$ & $\mathrm{O}$ & $\mathrm{O}$ & $\mathrm{O}$ & $\mathrm{O}$ & $\mathrm{X}$ & $\mathrm{O}$ & $\mathrm{O}$ & $\mathrm{O}$ \\
\hline & $\mathrm{L}$ & $\mathrm{X}$ & $\mathrm{X}$ & $\mathrm{O}$ & $\mathrm{O}$ & $\mathrm{X}$ & $\mathrm{X}$ & $\mathrm{X}$ & $\mathrm{X}$ & $\mathrm{O}$ & $\mathrm{O}$ & $\mathrm{X}$ & $\mathrm{X}$ & $\mathrm{O}$ \\
\hline \multirow{4}{*}{ Other models } & $\mathrm{M}$ & $\mathrm{X}$ & $\mathrm{X}$ & $\mathrm{O}$ & $\mathrm{O}$ & $\mathrm{X}$ & $\mathrm{O}$ & $\mathrm{X}$ & $\mathrm{X}$ & $\mathrm{X}$ & $\mathrm{X}$ & $\mathrm{O}$ & $\mathrm{O}$ & $\mathrm{X}$ \\
\hline & $\mathrm{N}$ & $\mathrm{X}$ & $\mathrm{X}$ & $\mathrm{O}$ & 0 & $\mathrm{X}$ & $\mathrm{O}$ & $X$ & $X$ & $X$ & $X$ & $\mathrm{O}$ & $\mathrm{O}$ & $\mathrm{X}$ \\
\hline & $\mathrm{O}$ & $X$ & $X$ & $X$ & $\mathrm{O}$ & $X$ & $X$ & $\mathrm{O}$ & $\mathrm{O}$ & $\mathrm{O}$ & $X$ & $\mathrm{O}$ & $X$ & $X$ \\
\hline & $\mathrm{P}$ & $X$ & $X$ & $\mathrm{X}$ & $\mathrm{O}$ & $X$ & $\mathrm{O}$ & $\mathrm{O}$ & $\mathrm{O}$ & $\mathrm{O}$ & $X$ & $\mathrm{O}$ & $X$ & $X$ \\
\hline
\end{tabular}

\begin{tabular}{l}
\hline *) Model ID \\
A = Basic [6],[8],[14] \\
B = Basic RSOC [6] \\
C = Sheperd [7] \\
D = Unnewehr [7] \\
E = Nernst [7] \\
F = RC [8] \\
G = Thevenin [9] \\
$\mathrm{H}=$ Runtime [8]
\end{tabular}

I = Runtime IV [8],[10]

$\mathrm{J}=$ Tremblay et al. [8],[11]

$\mathrm{K}=$ Jackey [8],[12]

$\mathrm{L}=$ Randles [13]

$\mathrm{M}=$ CIEMAT [14]

$\mathrm{N}=$ Monegon [14]

$\mathrm{O}=$ Impedance $[15],[16]$

$\mathrm{P}=$ Third order [17]

$\left.{ }^{* *}\right)$ Requirements and performance in modeling physical phenomena

$1=$ Voltage estimation during continuous current discharge [7]

$2=$ Transient behavior, large period pulse current [9]

$3=$ Transient behavior, short period pulse current [9]

$4=$ Self discharge [9], $5=$ Charge operation modeling [11]

$6=$ SOC estimation provided by adaptive parameters [13]

7 = Real-time parameters estimation [8],[10]

8 = Real-time and IV curve prediction [8],[10]

$9=$ Exponential operation area [11],[14], $10=$ Peukert effect [10]

$11=$ Memory effect

$12=\mathrm{SOH}$ estimation provided by adaptive parameters [13]

$13=$ Temperature effect [14]

$X=$ Requirement fulfilled $O=$ Requirement not fulfilled

constrained minimums formulation, a set of parameters can be assigned to each model in order to reduce the deviation among real and model voltage:

$$
[X] \cong\left(H^{T} \cdot H\right)^{-1} \cdot H^{T} \cdot\left[V_{\text {measured }}\right]
$$

Even in case of experimental data acquired at different temperatures, this identification method allows to obtain a good accuracy in the estimation of parameters. Anyway, since in the automotive applications the temperature fluctuations can be usually very large, it is often required the implementation of an estimation algorithms to continuously tune the parameters of the 
Table 2 Technical specifications of the main components in the test bench

\begin{tabular}{|c|c|c|c|c|c|c|c|}
\hline \multicolumn{2}{|c|}{ V panel } & \multicolumn{2}{|c|}{ Charge regulator } & \multicolumn{2}{|c|}{ Battery pack } & \multicolumn{2}{|c|}{$\begin{array}{c}\text { Stand-alone DC/AC converter (AC } \\
\text { loads) }\end{array}$} \\
\hline rated power & $250 \mathrm{~W}$ & system voltage & $24 \mathrm{~V}_{\mathrm{DC}}$ & technology & VRLA (x 8) & rated power & $2 \mathrm{~kW}$ \\
\hline $\mathrm{V}_{\mathrm{OC}}$ & $37.0 \mathrm{~V}_{\mathrm{DC}}$ & rated PV current & $20 \mathrm{~A}$ & neted ulto & & rated & \\
\hline $\mathrm{I}_{\mathrm{SC}}$ & $8.26 \mathrm{~A}$ & rated load & $20 \mathrm{~A}$ & rated voltage & $24 V_{D C}$ & input & $24 V_{D C}$ \\
\hline $\mathrm{V}_{\mathrm{MPP}}$ & $29.8 \mathrm{~V}_{\mathrm{DC}}$ & $\max \mathrm{PV}$ power & $520 \mathrm{~W}$ & rated canacity & $108 \mathrm{Ah}$ & rated outnut & $230 \mathrm{~V}_{\mathrm{AC}}$ \\
\hline $\mathrm{I}_{\mathrm{MPP}}$ & $7.72 \mathrm{~A}$ & $\max$ PV voltage & $100 \mathrm{~V}_{\mathrm{DC}}$ & & & & $50 \mathrm{~Hz}$ \\
\hline
\end{tabular}

circuit model especially for the simplest models listed in Table 1 [3]. The analysis of the sensitivity to temperature variations in parameters identification and the review of the methods to mitigate such effect is out of the scope of this work.

Considering the VRLA battery pack of Table 2, Table 3 lists the parameters identified for each model. The input experimental data have been acquired at various initial SOC values (from 10 to $100 \%$, steps of $10 \%$ ) and for different currents (from -5 to 20 A, steps of $1 \mathrm{~A}$ ). The current counting formula [6] is applied for those models that require a continuous evaluation of SOC as input data. The relation $E_{0}(S O C)$ is a quasi-straight line between the extreme points $(22.8 \mathrm{~V} ; 2 \%)$ and $(26.4 \mathrm{~V} ; 100 \%)$ in the plane $\left(E_{0} ; \mathrm{SOC}\right)$, as provided by the manufacturer.

Over 200 experimental tests at different current and SOC values have been scheduled. During the tests, the battery, having an initial SOC, is discharged (or charged) at a given current in a time period from a minimum of 2 hours to a maximum of 10 hours. For each couple of values $i(t)$ and SOC, the mean relative error and the error standard deviation have been calculated for each model:

error $_{\text {mean }}=\frac{\sum_{k=1}^{N} \text { error }_{k}}{k}$

$s t d=\sqrt{\frac{\sum_{k=1}^{N}\left(\text { error }_{k}-\text { error }_{\text {mean }}\right)^{2}}{N}}$

obtaining the 3D plots shown in Figure 6 and Figure 7. The standard deviation has been introduced because, in some cases, even if the mean error is close to zero, a significant deviation in most part of the waveform can be detected. Starting from data displayed in Figure 6, Figure 8 and Figure 9, there are shown the mean error values for different SOC values at a fixed current, while Figure 10 and Figure 11 show the mean error values for different current rates at a fixed SOC value.

Examining the experimental results, the first evidence is that the mean error in voltage estimation is strongly affected by the actual ESS state. In particular, a significant dependence on the SOC actual value can be observed: large deviations can be detected at low SOC values for almost all the models, Figure 8 and Figure 9. On the contrary, looking at Figure 10 and Figure 11 the influence of current variations on voltage estimation is quite

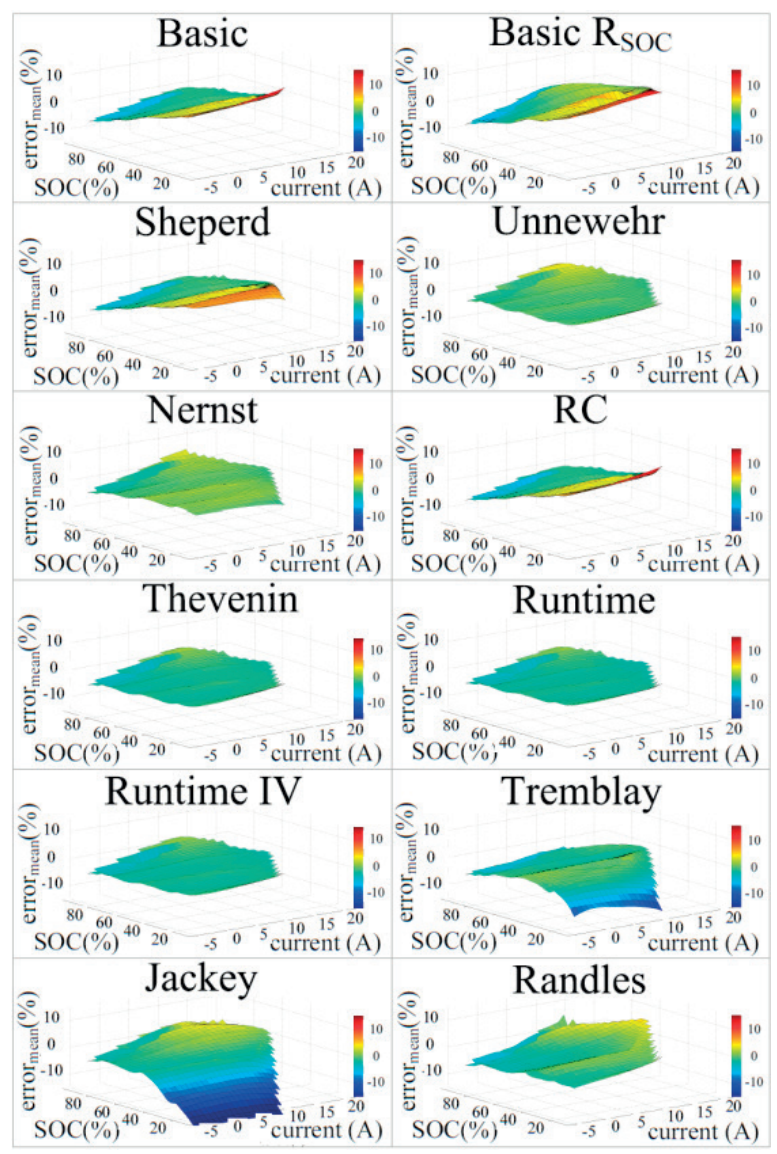

Figure $63 \mathrm{D}$ plots - Mean relative error related to the voltage estimation provided by each equivalent circuit model for different currents and SOC values

limited. Charge operation modeling typically implies a strong degradation in accuracy level due to complicated phenomena to be modeled, Figure 6 and Figure7. From Figure 7, there is no large difference between models in terms of standard deviations related to the error values. For each model, larger values of standard deviation can be identified at low or high SOC values. 
Table 3 Circuit models and parameters

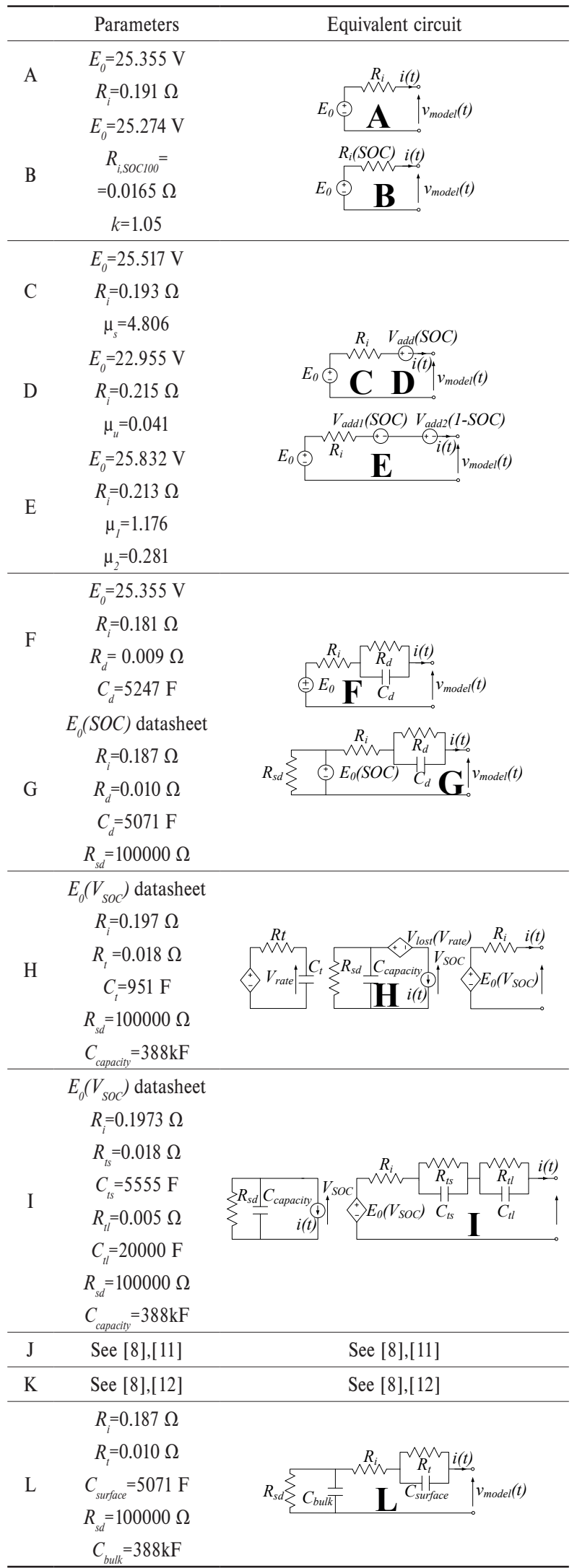

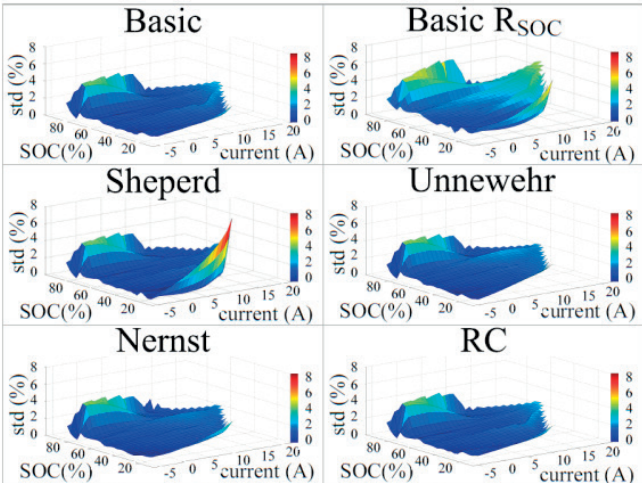

Thevenin

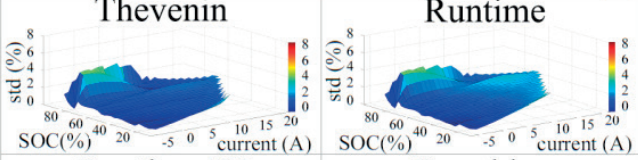

Runtime IV $\quad$ Tremblay

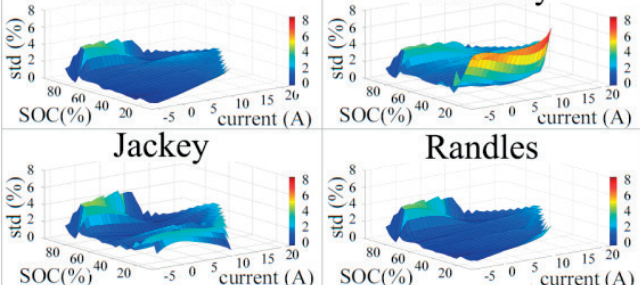

Figure 73 plots - Standard deviation related to error values in voltage estimation provided by each equivalent circuit for different currents and SOC

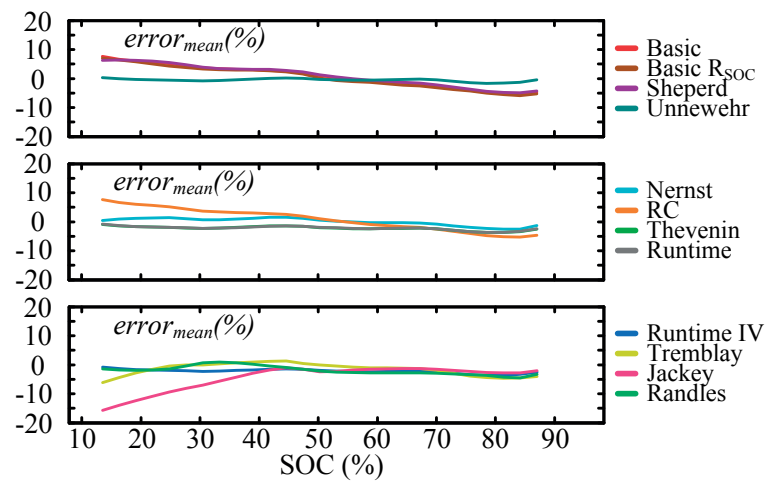

Figure 8 Mean error vs SOC, current is fixed -2 A

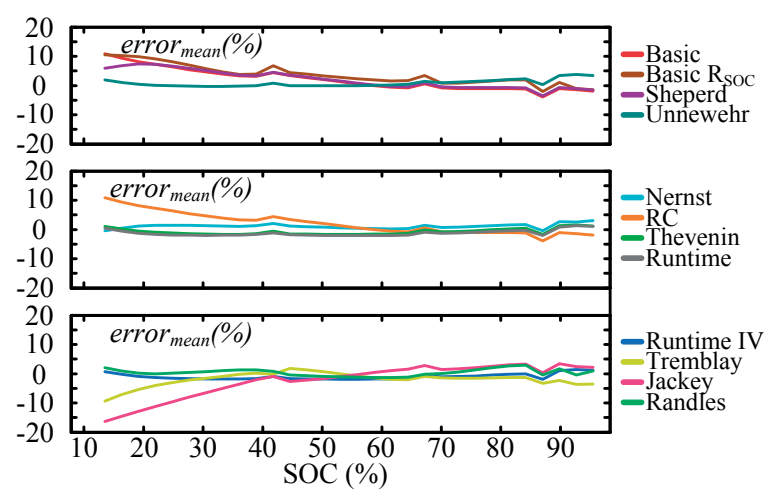

Figure 9 Mean error vs SOC, current is fixed $10 \mathrm{~A}$ 


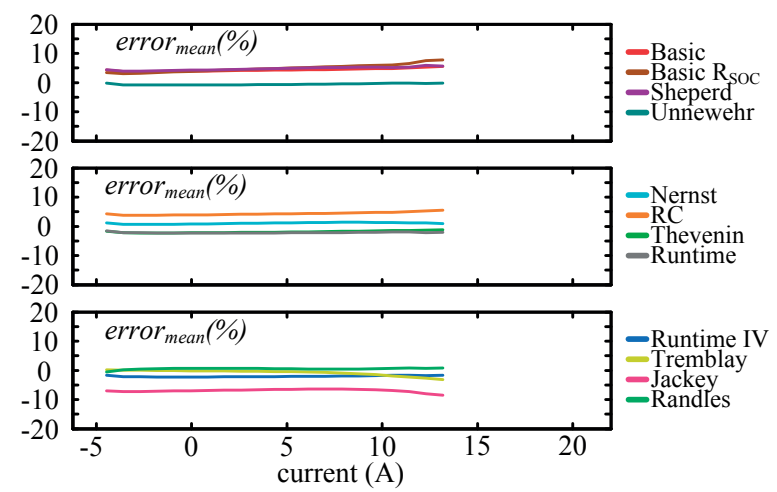

Figure 10 Mean error vs SOC, SOC is fixed 30\%

\section{Conclusions}

This paper deals with a study on the main equivalent electric circuits used in ESS modeling for automotive applications. The characteristics of each model have been studied and compared by means of a multi-criteria approach using both the data gathered by an in-depth literature review and those collected by performing several experimental tests. Using such a method, features and performance associated to each equivalent circuit have been

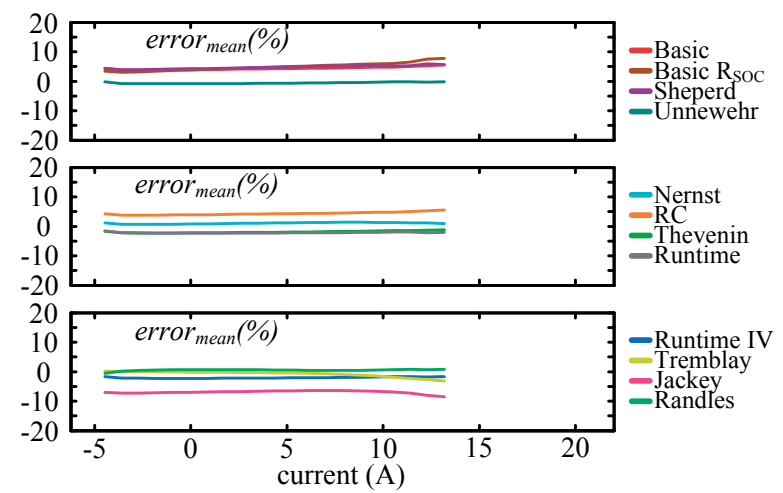

Figure 11 Mean error vs SOC, SOC is fixed $80 \%$

highlighted. The results of the comparative multi-criteria analysis show that Thevenin, Runtime and Runtime IV models can be considered as the best compromise between performance and complexity in standard automotive applications. Nevertheless, to reach a satisfactory accuracy in automotive applications, it is usually necessary to use an estimation algorithm capable to continuously tune the parameters of the circuit model in order to compensate their variation related to large temperature fluctuations, SOH degradation and so on.

\section{References}

[1] TUMMURU, N. R., MISHRA, M. K., SRINIVAS, S.: Dynamic Energy Management of Hybrid Energy Storage System with HighGain PV Converter. IEEE Transactions on Energy Conversion, 30(1), 150-160, 2015.

[2] CUGNET, M., DUBARRY, M., LYAW, B.: Secondary Batteries - Lead-Acid Systems - Modeling. Reference Module in Chemistry, Molecular Sciences and Chemical Engineering Encyclopedia of Electrochemical Power Sources, Elsevier, 816-828, 2009.

[3] CACCIATO, M., NOBILE, G., SCARCELlA, G., SCELBA, G.: Real-Time Model-Based Estimation of SOC and SOH for Energy Storage Systems. IEEE Transactions on Power Electronics, 32(1), 794-803, 2016.

[4] CACCIATO, M., NOBILE, G., PULVIRENTI, M., RACITI, A., SCARCELLA, G., SCELBA, G.: Energy Management in Parallel Hybrid Electric Vehicles Exploiting an Integrated Multi-Drives Topology. Proceedings of International Conference of Electrical and Electronic Technologies for Automotive, Italy, 2017.

[5] CACCIATO, M., NOBILE, G., SCARCELlA, G., SCELBA, G., SCIACCA, A. G.: Energy Management Optimization in StandAlone Power Supplies Using Online Estimation of Battery SOC. Proceedings of IEEE 18th European Conference on Power Electronics and Applications (EPE), Germany, 2016.

[6] SEAMAN, A., DAO, T., MCPHEE, J.: A Survey of Mathematical-Based Equivalent-Circuit and Electrochemical Battery Models for Hybrid and Electric Vehicle Simulation. Journal of Power Sources, 256, 410-423, 2014.

[7] HUSSEIN, A., BATARSEH, I.: An Overview of Generic Battery Models. Proceedings of IEEE Power and Energy Society General Meeting, USA, 1-6, 2011.

[8] MOUSAVI, S. M., NIKDEL, M: Various Battery Models for Various Simulation Studies and Applications. Renewable and Sustainable Energy Reviews, 32, 477-485, 2014.

[9] LI, J., MAZZOLA, M.: Accurate Battery Pack Modeling for Automotive Applications. Journal of Power Sources, 237, 215-228, 2013.

[10] CHEN, M., RINCON-MORA, A.: Accurate Electrical Battery Model Capable of Predicting Runtime and I-V Performance. IEEE Transactions on Energy Conversion, 21(2), 504-511, 2006.

[11] TREMBLAY, O., DESSAINT, L.: Experimental Validation of a Battery Dynamic Model for EV Applications. World Electric Vehicle Journal, 3, 1-10, 2009. 
[12] JACKEY, R. A.: A Simple, Effective Lead-Acid Battery Modeling Process for Electrical System Component Selection. Proceedings SAE World Congress and Exhibition, USA, paper 2007-01-0778, 2007.

[13] BHANGU, B. S., BINGHAM, C. M., STONE, D. A., BENTLEY, P.: Nonlinear Observer techniques for Prediction State-of-Charge and State-of-Health of Lead-Acid Batteries for Hybrid-Electric Vehicles. IEEE Transactions on Vehicular Technology, 54(3), 783794, 2005.

[14] ACHAIBOU, N., HADDADI, M., MALEK, A.: Lead Acid Batteries Simulation Including Experimental Validation. Journal of Power Sources, 185(2), 1484-1491, 2008.

[15] SALKIND, A., SINGH, P., CANNONE, A., ATWATER, T., WANG, X., REISNER, D.: Impedance Modeling of Intermediate Size Lead-Acid Batteries. Journal of Power Sources, 116, 174-184, 2003.

[16] STROE, D. I., SWIERCZYNSKI, M., STROE, A. I., KNAP, V., TEODORESCU, R., ANDREASEN, S. J.: Evaluation of Different Methods for Measuring the Impedance of Lithium-Ion Batteries during Ageing. Proceedings of Tenth International Conference on Ecological Vehicles and Renewable Energies (EVER), Monaco, 1-8, 2015.

[17] WANG, H., LI, G., LI, M., JIANG, Z., WANG, X., ZHAO, Q.: Third-Order Dynamic Model of a Lead Acid Battery for Use in Fuel Cell Vehicle Simulation. Proceedings of IEEE Mechatronic Science, Electric Engineering and Computer Conference (MEC), China, 715-720, 2011.

[18] ATTANASIO, R., CACCIATO M., CONSOli A., SCARCEllA G., TESTA A., GENNARO F.: A Novel Converter System for Fuel Cell Distributed Energy Generation. Proceedings of IEEE Annual Power Electronics Specialists Conference (PESC '05), Brazil, 1621-1627, 2005.

[19] CACCIATO M., CONSOli A., SCARCElla G., SCELBA G., TESTA A.: Modified Space-Vector-Modulation Technique for Common Mode Currents Reduction and Full Utilization of the DC bus. Proceedings of 24th Annual IEEE Applied Power Electronics Conference and Exposition (APEC 2009), USA, 109-115, 2009. 